\title{
Neonatal Sepsis in Nigeria 1: Introductory Overview
}

\author{
Ogbara $\mathrm{CN}^{1,2 *}$, Chime $\mathrm{HE}^{1}$ and Nwose $\mathrm{EU}^{1,3}$ \\ ${ }^{1}$ Department of Public \& Community Health, Novena University, Nigeria \\ ${ }^{2}$ Ministry of Health, Environmental. Bayelsa State Government, Yenagoa Nigeria \\ ${ }^{3}$ School of Community Health, Charles Sturt University, Australia
}

*Corresponding author: Ogbara CN, Department of Public \& Community Health, Novena University, Ogume, Nigeria

\section{ARTICLE INFO}

Received: 幽 May 24, 2021

Published: 蔧 June 01, 2021

Citation: Ogbara CN, Chime HE, Nwose EU. Neonatal Sepsis in Nigeria 1: Introductory Overview. Biomed J Sci \& Tech Res 36(2)-2021. BJSTR. MS.ID.005814.

Keywords: Epidemiological Determinants; Neonatal ICU; Infection Control

\section{ABSTRACT}

Objective: Neonatal sepsis has remained a public health concern and Nigeria is one of the leading contributors to the global phenomenon. As a prolog to update of the epidemiological situation, the objective of this paper is to present an introductory overview.

Method: A narrative essay method was adopted. Focus is basic information starting with historical landmark and including preventive measures amongst others.

Results: Neonatal sepsis has been known since the 1800s. It accounts for about $25 \%$ neonatal deaths. Preventive intervention by enforcement of hygienic practices can reduce hospital acquired infection rate from se $10 \%$ down to $2 \%$.

Conclusion: Enforcement of handwashing by carers is probably top of the necessary hygienic practices required for prevention. However, update on epidemiology is necessary.

\section{Introduction}

As far back in the 1800s, during the golden age of germ theory of disease, Ignaz Semmelweiss made a monumental observation about puerperal sepsis or sepsis that occurred during childbirth [13]. He noticed that in his words, "women who had assistance from midwives during delivery developed puerperal sepsis $2 \%$ of the time, and those who had help from medical students developed it $16 \% *$ of the time". A colleague was dying from an infection acquired during an autopsy accidentally cut himself and, Semmelweiss was able to recognize that the reason medical students influence the chances of developing puerperal sepsis was because they would perform autopsy and delivered babies without washing their hands. He instituted a policy forcing the medical students to wash their hands before seeing a patient and saw that the rate of puerperal sepsis reduces below 3\%. Unfortunately, it appears he was a pioneer of the idea of basic hygiene, as his policy was met with heavy criticism and he was fired. Over the course of the past 300 years Table 1, there has been an increased focus with contributions from several scientists on how to better understand and treat sepsis. In the early 1990s, a conference was held, an agreement as to what sepsis was defined and management strategies including laboratory diagnosis started getting articulated. This was modified by the 2001 conference but ultimately lead to the development of a distinction between an infection, sepsis, severe sepsis and septic shock [4].

Table 1: Historical landmark achievements on neonatal sepsis [1].

\begin{tabular}{|c|c|c|c|}
\hline Achievement & 1800s & 1900s & 2000s \\
\hline Discovery & $\begin{array}{c}\text { Ignaz } \\
\text { Semmelweiss }\end{array}$ & & \\
\hline $\begin{array}{c}\text { Management } \\
\text { strategy }\end{array}$ & & Edward Frank & \\
\hline $\begin{array}{c}\text { Modern } \\
\text { guidelines }\end{array}$ & & & Int'l committee \\
\hline
\end{tabular}

\section{Classification of Neonatal Sepsis}

Neonatal Sepsis is categorized in to two phases based on the time of presentation after birth. The phases include Early-Onset 
sepsis (EOS) and Late-Onset sepsis (LOS). EOS refers to Sepsis in neonatal at or before 72 hours after birth and is generally caused by the transmission of a pathogens from the female genitourinary system to the fetus thereby exposing the neonates to infection during delivery. LOS transmission occurs after the delivery of a neonate usually 3 to 4 days after birth [5]. The pathogens gained entry from the environment, such as contact from health care worker or caregivers. Late-Onset sepsis may also be caused by a late manifestation of vertically transmitted infection, infants that require intravascular catheter insertion, or other invasive procedure that disrupt the mucosa are at risk of developing LOS [4]

\section{Stages of Sepsis}

There are three stages of sepsis, they include: sepsis, severe sepsis and septic shock. Sepsis is a life-threatening illness caused by the body response to an infection. Sepsis develops when the immune system releases into the bloodstream of a chemical to fight an infection which causes inflammation throughout the body thereby leading to symptoms such as fever above 101 of $\left(38^{\circ} \mathrm{C}\right)$ or temperature below 96.8 of $\left(36^{\circ} \mathrm{C}\right)$, heart rate higher than 90 breaths per minute, breathing rate higher than 20 breaths per minute.

Severe sepsis occurs when there is organ failure. The individual must have one or more of the following signs to be diagnosed with severe sepsis. Patches of discolored skin, decrease urination, changes in mental ability, low platelet (blood clotting cell) count, problem in breathing, abnormal heart functions, chill due to fall in body temperature, unconsciousness, esteem weakness [6]. Septic shock is when there is an experience in significant drop of blood pressure that can lead to respiratory or heart failure, shock, failure of other organs and death. The inflammation resulting from sepsis causes tiny blood clots to form, as this can block oxygen and nutrients from reaching the vital organs. Septic shock is the most common cause of death in intensive care unit [7].

\section{Causes of Neonatal Sepsis}

Bacteria that are known to cause Sepsis in newborn are: E. coli, Group B streptococcus, Neisseria Meningitis, Salmonella, Haemophylus Influenza Type B, and Listeria Monocytogenes. The herpes simplex virus (HSV) family and existing medical condition can as well cause sepsis. A mother's birth canal contains bacteria, and in a situation where the mother has an active infection during delivery, the baby can swallow or breathe in the contaminated fluid through the birth canal, and when this happens, the bacteria or viruses get into the lungs and blood of the baby, leading to ill health during childbirth or within few days after birth [4]. In Nigeria as with other countries, the most common cause of EOS is Group B Streptococcus (GBS), followed by Escherichia Coli isolated in onefourth of episodes [8]. The remaining causes of EOS are caused by Staphylococcus aureus, Coagulas-negative Staphylococcus
(CoNS), and other gram- negative bacteria amongst others $[9,10]$. Furthermore, in both Nigeria and developing countries, klebsiella sp, E. Coli, and Staphylococcus aureus as well as GBS also constitute the most common nosocomial neonatal sepsis [11-13]. Some maternal factors associated with EOS include; maternal GBS colonization (if untreated before labour), rupture of membranes, maternal urinary tract infection, poor prenatal care, poor maternal nutrition amongst others $[9,14,15]$; while LOS causes include hospital procedures such as venous catheterization and healthcare professionals' noncompliance to aspeti principles $[14,16,17]$. Hence, continuous education and monitoring of healthcare staff on hospital acquired infection and necessary compliance is part of infectious disease control in the neonatal intensive care units [13].

\section{Signs and Symptoms of Neonatal Sepsis}

Signs and symptoms of neonatal sepsis may depend on the severity of the infection, it may exhibit a variety of symptoms such as; reduced appetite and reluctance to feeding or not drinking for more than 8 hours, tendency to vomit after feeding, high body temperature, above 100.4 degree Fahrenheit, increase irritability and cranky behavior, change in heart rate (both high and low rate) depending on infection stage, eye and skin may look yellow due to jaundice (eyes may have sunken appearance), a swelling in the stomach region, decrease in urination (not passing urine in more than 12 hours), change in skin tone ( pale and patchy skin),reduction of blood platelet count, a decrease in blood pressure, bulging of the fontanel, a problem in taking breath, lethargic or floppy movements $[4,11,13,18]$. Sepsis is a medical emergency that is characterized with a disease condition with multiple causative organisms, and people with sepsis can present various signs and symptoms at different times. Warning signs and symptoms include fever, low temperature, shivering, altered mental status, difficult breathing/ rapid breathing, and increased heart rate, weak pules/low blood pressure, low urine output, mottled skin, cool extremities, and extreme body pain or discomfort $[4,6,7,16]$.

\section{Diagnosis of Neonatal Sepsis}

To carryout diagnosis for neonatal sepsis is important because the infection may present a very serious threat to the neonate. It requires an urgent need to ascertain if the baby has sepsis or not. Sepsis can be difficult to identify mostly in the initial stages and it presents a considerable diagnostic challenge to emergency department and intensive care clinicians. The neonate may have fever, increased heart rate or breathe problem but to be sure is through diagnostic test. A blood sample will be taken as well as a blood count. A high white blood cell correlates to the condition, and a C-reactive protein test may also be performed, to ascertain the particular bacteria or virus responsible for the ill health (sepsis). A urine culture may be done to identify the cause of infection, if the child is coughing and throwing up mucus, the mucus may also 
be tested, if there is a wound, the secretions from the wound can be tested to identify bacteria causing the infection. A Computerized Tomography or C.T scan can be taken to identify the location of the infection internally. A lumber puncture or spinal tap could be done to gain a spinal fluid, to check for meningitis, an infection of the membranes that cover the brain $[4,10,11,18]$. One of the major difficulties in the management of neonatal sepsis is getting an accurate diagnosis, as most Neonates presentation multiple conditions that looks like neonatal sepsis. An auxiliary test has limited value and are difficult to interpret due to low sensitivity and changing normal ranges in the neonatal period. Blood culture is the best standard for the diagnosis and complete blood cell count is also difficult to interpret in the neonatal period because it varies significantly with day of life and gestational age. There is new nonculture -based method that is being used to improve the diagnosis process. CD64 neutrophil marker has a higher sensitivity and specificity. The method has the additional advantage of acquiring small portion of blood, they rise very rapidly after a bacterial infection and normalize before 24 hours, limiting their clinical use [11].

\section{Neonatal Sepsis Infection Control}

It is opined that neonatal sepsis may be prevented by good perinatal care, which include the control of any bacteria in the mother before it is spread during pregnancy and birth. However, he suggested the following as measures to prevent the disease: avoid unnecessary separation of newborn from mother, disinfection, hand washing before delivering and handling the baby, good hygiene and cleanliness during delivery, appropriate umbilical cord care, and appropriate eye care of the infant [19]. WHO notes that for prevention of late-onset sepsis, hand washing or use of gel as hand sanitizer before contact with the patient, (after risk of exposure to biological fluids) after contact with the patient, after contact with areas near the patient, appropriate and well- define care bundles, with central intravascular catheters and endotracheal tubes that are closely followed to reduce contamination. Breast milk is also important due to its concentration of $\operatorname{IgA}$ and oligosaccharides that gives it anti infectious properties. The exclusive use of breast milk results in diverse intestinal microbiota, which lead to a lower probability of infections. With regards to before delivery, WHO states that it is important to improve maternal health and nutritional before delivery as this is associated with improved neonatal health outcome. The intake of protein-calorie and multiple micro supplementations have demonstrated significant improvement in the level of prematurity and birth weight and different impact on mortality [20].

During Labour and Delivery: Clean delivery practices and hand washing during delivery has reduce the rate of Neonatal Sepsis. A study from Malawi and Nepal indicates that maternal antisepsis intervention such as vaginal chlorhexidine during labour may have a significant impact on the rate of neonatal mortality and sepsis in developing countries [13].

After Delivery: Addressing infection and newborn sepsis require improved intra-partum practice, such as hand washing, by birth attendants, disinfection and sterilization of equipment, minimization of vaginal examinations, prompt diagnosis and treatment of prolonged labour, exclusive breast feeding, clean cord care, improve maternal health and nutrition, maternal and neonatal immunization and antibiotic prophylaxis [21]. It has been highlighted that the following steps are necessary infection preventive measures [19].

a) to maintain a good hygiene and wash hand often-especially when around or caring for children,

b) Proper cooking of meat until it is well done, any other form of meat sold should be reheated before consumption

c) to avoid unpasteurized (raw) milk and food made from it

d) Avoid people with communicable infection such as chicken pox or rubella; and every woman to get vaccinated before pregnancy

e) prompt antenatal visit, and

f) pregnant women to screen for GBS, especially close to delivery

g) Also screen for sexual transmitted infections (STDs) including HIV, Hepatitis B

The principle of cleaning and disinfecting of equipment's/ environment is important as it prevents and reduce the level of disease incidence of health care associated infection [21]. Sterilization and disinfection are the basic components of hospital infection control. Hospitals should endeavor to adhere and observe its own guidelines of disinfection and sterilization pattern to curb the spread of faction within our health care system [22].

\section{Management of Neonatal Sepsis - Treatment}

It has been reported that neonatal sepsis is a frequent cause of neonatal morbidity and mortality and its management is always a challenge. When neonatal sepsis is suspected, there is the need to always collect samples for bacteriological analysis before starting the empirical treatment. The empirical antibiotic therapy and the choice of the particular treatment regimen are important. Vancomycin should not be routinely used in the empirical antibiotic regimen in late neonatal sepsis, and the main protective mechanisms against neonatal sepsis are hand washing and the use of breast milk [18]. Management of a child with neonatal sepsis has several challenges hence it requires adequate and proper supportive care $[11,13,18,21,23]$. The child is nursed in a temperature-regulated environment to avoid fluctuations in body temperature. Oxygen saturation is also monitored very closely. Mechanical ventilator 
may have to be initiated if necessary. If the infant is hemodynamic unstable, intravenous fluid should be administered and the infant is to be monitored of hypo hyperglycemia. Parked red cells are frozen plasma, can be used in the case of anemia or bleeding diathesis. There cannot be a single recommendation of antibiotic regimen (antimicrobial therapy) of neonatal sepsis for all settings. The choice of antibiotic depends on the prevailing flora in the given unit and their antimicrobial sensitivity [23].

In the management of neonatal sepsis, the use of intravenous benzyl penicillin with gentamicin as the first-line antibiotic of choice for empirical treatment of EONS is crucial, except in occasions of bacterial resistance. Laboratory tests are expectedly done profusely, especially where sepsis is strongly suspected, i.e. given the possibility of false negative blood culture at 48 hours [24]. It is advisable to repeat blood culture and continue antibiotics for at least five days providing infective indices have normalized. Another approach is to continue antibiotics for 48 hours after indices are normal [25]. Hospital acquired (nosocomial) infection is one of the major problems most neonates have during their stay in the NICU. The nosocomial infections can be prevented and controlled through observing standard precautions, personal/ hand hygiene and good environmental hygiene. Hence preventive medicine practices by the healthcare providers in NICU remains a very valid measure [13].

\section{Adherence to Infection Control Rules in the Intensive Care Unit}

An Intensive Care Unit (ICU) is a special department of a hospital or a health care facility that provides intensive treatment to neonates or critically ill patients. Most of the ICN patients are those referred from other hospitals, medical institution, emergency department within the same hospital if the situation is not improving as expected, or after surgery if the surgery is very invasive and require close observation [26]. NICU is a separate place within the hospital setting were newborn babies who need intensive medical care are kept for close observation and treatment. The unit is usually specifically equipped with technology and trained professionals who give special care to all neonates. The unit may also care for babies who are not severely sick but do need special care. Most admitted babies are preterm [5,13]. An effective means of infection control in NICU is to acknowledge and identify sources of the infections - viz: the mothers, visitors and healthcare workers as well as use of contaminated material in patient care. Therefore, some of the precautions on how to prevent nosocomial infection in the NICU include: clean the immediate environment, applications of standard policies and procedures of infectious disease controls in healthcare facilities. In this regard, compliance of the healthcare workers is very paramount and so is the continuous retraining of the staff. In a study that evaluated camera monitoring and feedback (CMAF) as a means of enforcing NICU staff compliance to infectious control principles [13], it was observed that nosocomial infection rate reduced, while the healthcare workers' compliance on hand hygiene improved (Figure 1). However, this study was done overseas. Therefore, the level of compliance to infectious control principles in NICU and/or potentials for improvement at Bayelsa State are yet unknown hence the justification for research evaluation.

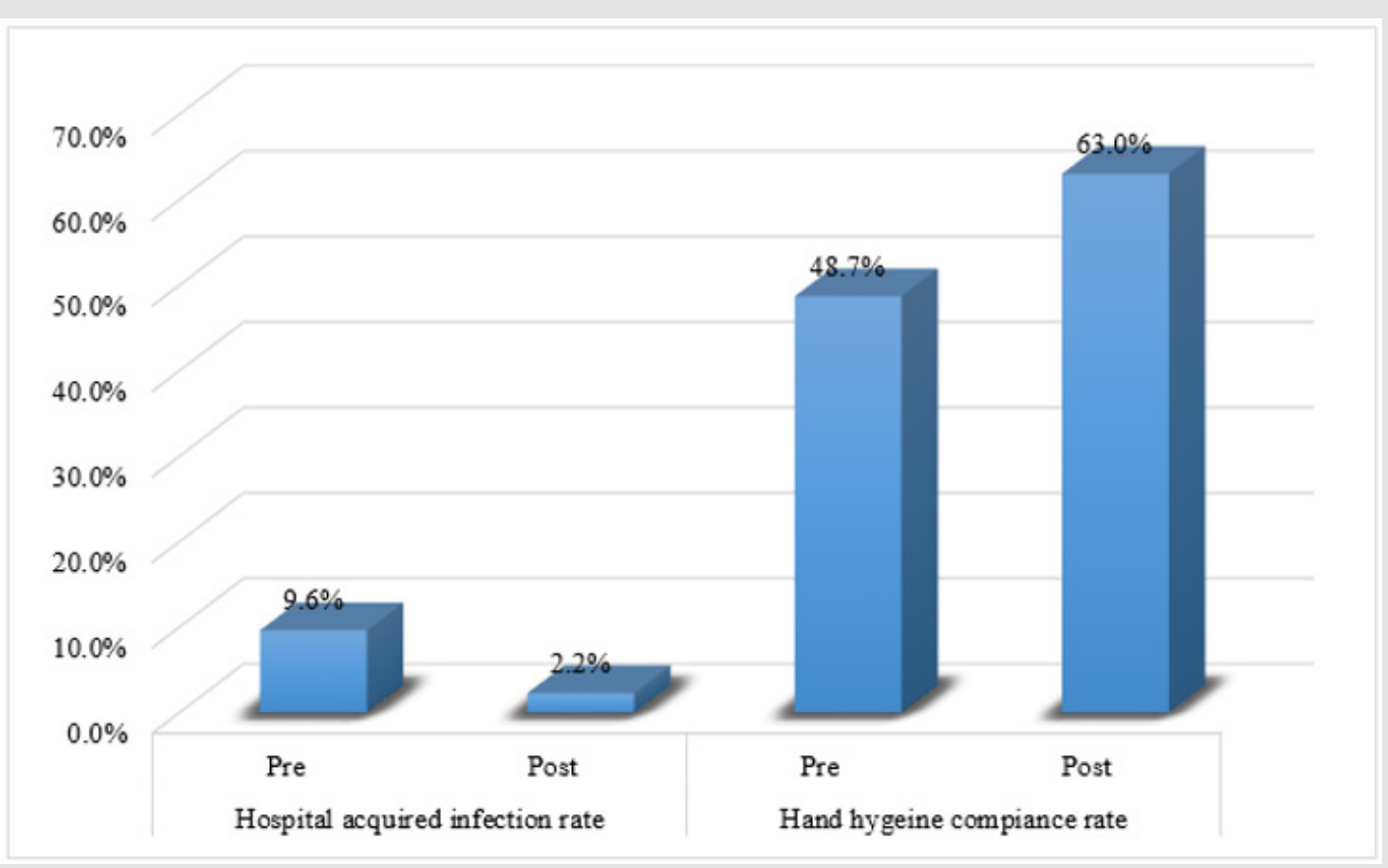

Figure 1: Reported effects of using camera in neonatal infection control [13]. 


\section{Risk Factors Associated with Neonatal Sepsis}

A lot of factors are associated to the high number of neonatal deaths from infection. These include under- recognition of illness, delay of care seeking by the family, lack of access to appropriatetrained health worker and high- quality service to manage the illness. Even if quality of service is available, the cost of treatment is beyond the reach of many. It is certain that many neonatal deaths occur in the community, without the child having the health care service needed. Immature Immune System of the neonate is a larger contributing factor in the development of neonatal sepsis [27]. At this juncture, it is pertinent to note that neonatal sepsis contributes about $25 \%$ of neonatal deaths. There are several other factors confounding neonatal mortality. In fact, there are other infectious diseases apart from sepsis (Figure 2).

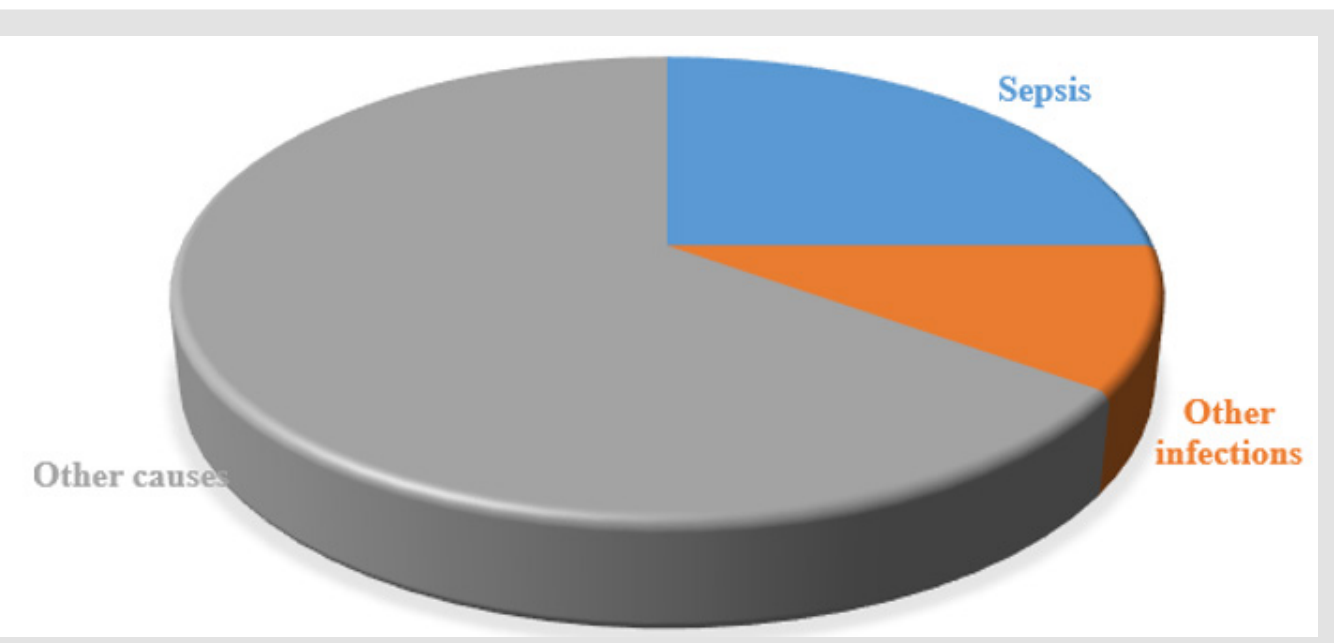

Figure 2: Estimated contribution of sepsis to annual neonatal deaths [20, 27].

\section{Socio-Economic Predisposal Factors}

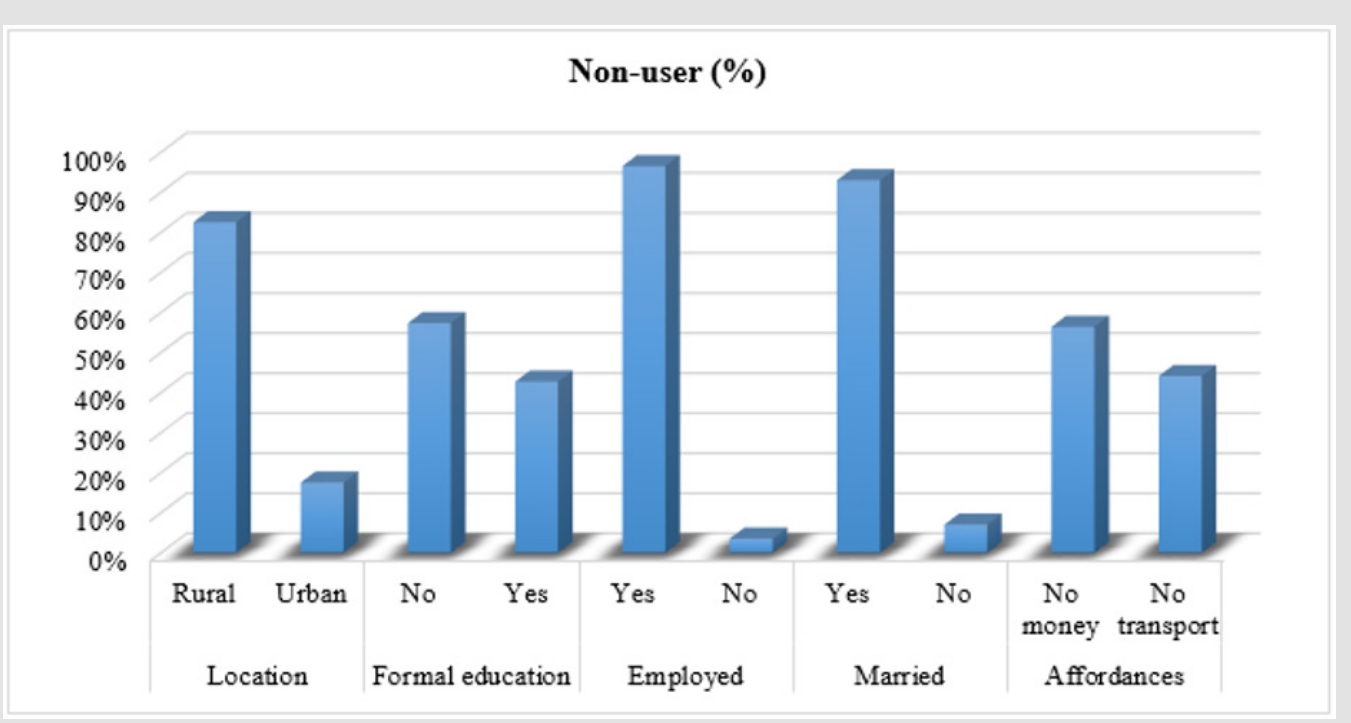

Figure 3: Distribution of mothers who did not use ANC in a Nigerian survey [30].

Working during pregnancy is a bit stressful to such mothers as they go through physical and hormonal changes which can give rise to mood swings, pains/ aches and fatigue. With the health situation, coupled with the work stress may be difficult for her to handle, as such situations (stressful job) can impose a negative impact on the mother and fetus health [18]. Stress during pregnancy is one of the determinants of health of the fetus regardless of how early the gestational age may be. Studies have shown that stress during pregnancy can cause adverse effect to the brain and development of the fetus [28]. Oxidative stress constitutes the biochemical basis of distress, which can negatively impact pregnancy, causing complications like preterm birth, low birth weight, and even sleep and behavioral disorder in young children [29]. In a Nigerian study that investigated determinants of usage of antenatal clinic (ANC) 
among women, interesting observations included up to $4 \%$ of the highly educated as well as the very wealthy among those who never used ANC services [30]. More interesting is the reported observation of the married and employed being non-users than the unemployed and unmarried, respectively. On a dichotomous scale, though, majority of the non-users were rural dwellers, those with no formal education (Figure 3). This observation on affordances was corroborated by another study from Delta State [31].

\section{Conclusion}

The burden of neonatal sepsis exists in Bayelsa state Nigeria as in other parts of the world. However, there is dearth of information regarding epidemiological improvement and infection control enforcement. It is known that enforcement among the healthcare workers improves compliance by staff and reduces neonatal nosocomial infections. What is unknown includes level of compliance in Bayelsa State NICUs and potential for improvement. Therefore, there is need to evaluate both NICU healthcare workers as well as mothers of babies.

\section{References}

1. Ryding S (2020) Sepsis history. News-Medical.Net, Azo Network.

2. Raju TN (1999) Ignác Semmelweis and the etiology of fetal and neonatal sepsis. J Perinatol 19: 307-310.

3. Vincent JL, Abraham E (2005) The last 100 years of sepsis. Am J Respir Crit Care Med 173(3): 256-263.

4. Ershad M, Mostafa A, Dela Cruz M (2019) Neonatal sepsis. Curr Emerg Hosp Med Rep 7: 83-90.

5. Wynn JL (2016) Defining neonatal sepsis. Curr Opin Pediatr 28(2): 135140.

6. Powrie S, Norman J (1976) Septicaemia Br J Anaesth 48(1): 41-47.

7. Johnson S (2020) Septic shock. Healthline Media (online).

8. Medugu N, Iregbu K Iroh, Tam P-Y (2018) Aetiology of neonatal sepsis in Nigeria, and relevance of Group b streptococcus: A systematic review. PLOS ONE 2018; 13: e0200350.

9. Adedokun AA, Onosakponome EO, Nyenke CU (2020) Early onset and late onset of neonatal sepsis in a tertiary hospital, South-South, Nigeria. Journal of Advances in Microbiology 20: 19-29.

10. Peterside O, Pondei K, Akinbami FO (2015) Bacteriological profile and antibiotic susceptibility pattern of neonatal sepsis at a Teaching Hospital in Bayelsa State, Nigeria. Trop Med Health 43(3): 183-190.

11. Zea-Vera A, Ochoa TJ (2015) Challenges in the diagnosis and management of neonatal sepsis. Journal of tropical pediatrics 61(1): 1-13.

12. Amoran OE, Onwube 00 (2013) Infection control and practice of standard precautions among healthcare workers in northern Nigeria. Journal of global infectious diseases 5(4): 156-163.

13. Karabay M, Kaya G, Hafizoglu T (2019) Effect of camera monitoring and feedback along with training on hospital infection rate in a neonatal intensive care unit. Ann Clin Microbiol Antimicrob 18: 35.

14. Leal YA, Álvarez-Nemegyei J, Velázquez JR, Ulises Rosado-Quiab, Nidia Diego-Rodríguez, et al. (2012) Risk factors and prognosis for neonatal sepsis in southeastern Mexico: analysis of a four-year historic cohort follow-up. BMC pregnancy and childbirth 2012; 12: 48.
15. Ogundare E, Akintayo A, Aladekomo T, Lateef Adeyemi, Tinuade Ogunlesi, et al. (2019) Presentation and outcomes of early and late onset neonatal sepsis in a Nigerian Hospital. African health sciences 2019; 19(3): 2390-2399.

16. Afroza S (2006) Neonatal sepsis - a global problem: an overview. Mymensingh medical journal : MMJ 15(1): 108-114.

17. Ezeh OK, Agho KE, Dibley MJ, John Hall, Andrew Nicholas, et al. (2014) Determinants of neonatal mortality in Nigeria: evidence from the 2008 demographic and health survey. BMC Public Health 14: 521.

18. Procianoy RS, Silveira RC (2020) The challenges of neonatal sepsis management. J Pediatr (Rio J) 96 Suppl 1: 80-86.

19. Rathore MH, Jackson MA (2017) Infection prevention and control in pediatric ambulatory settings. Pediatrics 140: e20172857.

20. World Health Organization. Neonatal sepsis - a major killer to be tackled in communities (2009, accessed $8^{\text {th }}$ Oct, 2020).

21. Sehulster L, Chinn RY (2003) Guidelines for environmental infection control in health-care facilities. Recommendations of CDC and the Healthcare Infection Control Practices Advisory Committee (HICPAC). MMWR Recomm Rep 52: 1-42.

22. Mohapatra S (2017) Sterilization and disinfection. Essentials of Neuroanesthesia 929-944.

23. Bang AT, Bang RA, Baitule SB (1999) Effect of home-based neonatal care and management of sepsis on neonatal mortality: field trial in rural India. Lancet 354(9194): 1955-1961.

24. Walker SAN, Cormier M, Elligsen M, Julie Choudhury, Asaph Rolnitsky, et al. (2019) Development, evaluation and validation of a screening tool for late onset bacteremia in neonates - a pilot study. BMC Pediatr 19: 253.

25. Sharma D, Farahbakhsh N, Shastri S (2018) Biomarkers for diagnosis of neonatal sepsis: a literature review. The journal of maternal-fetal \& neonatal medicine: the official journal of the European Association of Perinatal Medicine, the Federation of Asia and Oceania Perinatal Societies, the International Society of Perinatal Obstet 31: 1646-1659.

26. Smith VC, Hwang SS, Dukhovny D, S Young, D M Pursley, et al. (2013) Neonatal intensive care unit discharge preparation, family readiness and infant outcomes: connecting the dots. J Perinatol 33: 415-421.

27. Qazi SA, Stoll BJ (2009) Neonatal sepsis: a major global public health challenge. Pediatr Infect Dis J 28: S1-2.

28. Coussons-Read ME (2013) Effects of prenatal stress on pregnancy and human development: mechanisms and pathways. Obstet Med 6: 52-57.

29. Bharadwaj S, Bhat VB, Vickneswaran (2018) Oxidative stress in preeclamptic mother - newborn dyads and its correlation with early neonatal outcome - a case control study. The journal of maternal-fetal \& neonatal medicine : the official journal of the European Association of Perinatal Medicine, the Federation of Asia and Oceania Perinatal Societies, the International Society of Perinatal Obstet 31: 1548-1553.

30. Fagbamigbe AF, Idemudia ES (2015) Barriers to antenatal care use in Nigeria: evidences from non-users and implications for maternal health programming. BMC pregnancy and childbirth 2015; 15: 95.

31. Nwose EU, Mogbusiaghan M, Bwititi PT, G Adoh, O Agofure, et al. (2019) Barriers in determining prevalence of type 2 diabetes mellitus among postpartum GDM: The research and retraining needs of healthcare professionals. Diabetes \& metabolic syndrome 13(4): 2533-2539. 
ISSN: 2574-1241

DOI: 10.26717/BJSTR.2021.36.005814

Ogbara CN. Biomed J Sci \& Tech Res

(C) This work is licensed under Creative

Submission Link: https://biomedres.us/submit-manuscript.php

$\begin{array}{ll}\text { BIOMEDICAL } & \text { Assets of Publishing with us } \\ \text { RESEARCHES } & \text { - Global archiving of articles } \\ & \text { - Immediate, unrestricted online access } \\ & \text { - Rigorous Peer Review Process } \\ & \text { - Authors Retain Copyrights } \\ & \end{array}$

